\title{
A Comparative Study on Compliment Words between Chinese Culture and English Culture and Its Enlightenment on Chinese Teaching as a Second Language
}

\author{
Ma Ning \\ Xinyang Agriculture and Forestry University, Xinyang, Henan Province 464000
}

\begin{abstract}
Keywords: Compliment words; Intercultural Communication; Chinese-English Cultural Difference; Culture Teaching
\end{abstract}

\begin{abstract}
Due to the differences between Chinese culture and English culture, people's language habits and values are quite different. Therefore, there are also obvious cultural differences in many communicative activities. This paper mainly compares and studies the similarities and differences of compliment words in Chinese culture and English culture, then tries to provide some inspiration for Chinese teaching as a second language.
\end{abstract}

\section{Introduction}

H. P. Grice (1968) The advent of the principle of conversational cooperation laid a good foundation for the contemporary pragmatic theory and pragmatic analysis. Grice's communicative cooperation principle states that to understand the speaker's implicature can not be decoded by language, instead, it should rely on pragmatic reasoning (inference). Pragmatic reasoning is achieved on the basis of the contextual assumption as well as the general principles in communication. Grice believes that in all the language communication, the speaker and hearer have a tacit understanding and cooperation, so that the whole speaking during the conversation conforms to the goals and direction of communication. This tacit understanding and cooperation is that people believe that when talking to each other we need to attach great importance to cooperation, and comply with principles and guidelines such as being true, sufficient, relevant and clear etc.

However, in the actual conversation analysis, we have learnt that there is still some ambiguity in Grice's doctrine. He didn't elaborate how the rules in cooperation principles originate, nor did he explain in which way people worked to master and obey these principles and laws. Especially, He did not talk about whether speakers and listeners from different cultural backgrounds enjoy the same the different linguistic and cultural background of the speaker and hearer have the same tacit understanding and cooperation, so that people are not clear about whether these guidelines and principles are generally applicable to the exchange of different languages and whether they bring different cultural characteristics. If they do not bring same cultural identity, what condition it will be for people speaking different languages to use the application of these principles and guidelines? In order to understand conversation cooperation under different languages cultural backgrounds, this article takes English-Chinese compliment words as an example for discussion.

Compliment words are words that make people pleased. Compliment words is one of the most commonly used verbal acts in daily life. However, there are considerable differences between English and Chinese compliment words, this article attempts to explore the similarities and differences between English and Chinese compliment words, at the same time social and cultural factors that produce cultural differences will also be briefly analyzed in order to better guide cross-cultural communication practices.

Compliment words, as one of the most frequently used languages, arouses scholars' extensive attention and research. Since the publication of Compliment Responses by linguist Pomerantz in 1978, many linguistic linguists have studied compliment words and responses to them, such as Manes, Wolfson, Herbert, and Holmes. The domestic research on the compliment language and its response has begun to attract more attention in recent years with the development of linguistics in 
China. The article "Politeness, Pragmatics and Culture" published by Gu Yue-guo in "Foreign Language Teaching and Research" in 1992 elaborates on the fact that politeness, pragmatics and culture have obtained certain positions or skills for people, and with them, people are able to been continuously developed in their practice.

Compliment words is one of many verbal acts, and its implementation as an act, it necessarily has its intended purpose. Compliment verbal behavior can be used to create an atmosphere of mutual trust so as to achieve better interaction and realize more effective coordination and promotion of harmonious interpersonal communication purpose. In the process of intercultural communication, there should be a macroscopic understanding of the mainstream culture that affects people's value orientation in different cultural backgrounds. For different languages, some differences among people in the context of complimenting, comprehending and complimenting objects and their use must be well understood. This article is exactly based on this idea and the conclusion of the related achievements of other people, it is of great significance to study whether the speech act of compliment words affect the daily speech communication, especially the intercultural communication. A preliminary analysis and summary of the details required for the benefit of the interlocutors is given to draw attention from intercultural communicators in their intercultural activities.

Compliment words plays an indispensable role in every cultural life, and it is widely used in people's daily social interaction. As a positive assessment of the behavior of others or others, compliment words is a lubricant of social interpersonal relations and plays a crucial function in creating a pleasant conversation atmosphere, shortening the distance between conversation participants and establishing harmonious interpersonal relationships. However, not every culture has a consistent approach to communication, and communicators from different countries and cultures respond differently to it. Nowadays, with the rapid development of information technology, people from different countries and cultural backgrounds also communicate more and more frequently. Proper use and response of compliment words is an important part of the success of communication. There is a great difference between Chinese and English in response to compliments, and strengthening awareness in this field is of great importance to intercultural communication.

The basic structure of compliment words is a kind of "matching structure." Its structural features are the two linguistic acts of "complimenting and answering", both indispensable. From the social behavior point of view, compliment words reflect the judgments, evaluation, appreciation and praise of people and things in daily life communication, and also the norms of the socio-cultural value. Therefore, different cultural backgrounds make the content, language form, response mode, and pragmatic differences of compliment words imprinted with different social and cultural rules. When people in different cultural backgrounds use the same language, they usually respond differently to the same language phenomenon due to differences in their cultural roots. These responses are acceptable to some cultures but may not be accepted for other particular cultures. The research on the mode of conversational Chinese-Western compliment words shows that there are typical differences between Chinese and the western countries in using compliment words. At the same time, the differences in the mode of conversation largely reflect the influence of different cultural factors on Chinese and westerners, and also show that Chinese and westerners have different attitudes and values.

It is well-known that second-language learners already have had a formalization of the target language culture before they learn the second language. The so-called stereotype refers to the overly generalized and simplistic beliefs and attitudes of one group to another, which is a kind of over-generalized cognitive way and thinking way. We always hear people say that Jews are smart, French are romantic, Americans are humorous, British are gentlemen, and Chinese are industrious. Some of these phenomena originated from educational materials or publicity materials, and some are given by someone we know. We are exaggerating the characteristics of the group and ignoring the individual characteristics, we often equate a person we know with a country. Let us briefly discuss the similarities and cultural differences between Chinese and English cultures in using 
compliment words so that we can better understand how to properly commend each other and how to decently respond to each other's compliments when cross-cultural communications are taking place, which is pretty significant for our daily communication and teaching Chinese as a foreign language.

\section{Similarities between Chinese and English compliment words}

The degree of politeness embodied in verbal communication marks, in a certain sense, shows the degree of civilization of a society and reflects the spiritual outlook of a nation. China is an ancient civilization and state of ceremonies. In interpersonal relationships, people attach great importance to the humble, respectful attitude and courtesy language. English culture also fully embodies the expression of politeness principle in interaction. The politeness principle is reflected in the behavior. There are many similarities between Chinese and English in terms of praise, gratitude and other expressions. Such as:

(1) Your fried dishes are delicious.

(2) Thank you for your help.

Modesty is generally considered to be the virtue of Chinese culture, but it is also an important element in English culture. In the modest expression of Chinese, compliments and appraisals from each other generally do not adopt fully agreed responses but use a strategy of "downsizing" to express their consent. Such as:

(1) A: You just danced very well.

B: Really? I think was little nervous just now.

(2) A: You have a nice apartment.

$\mathrm{B}$ : Yes. The rent is expensive. It is a burden.

\section{The differences between compliment words in Chinese culture and English culture}

A U.S. student and a Chinese student were invited to visit a Japanese friend's house. Although later Chinese students told American students that Japanese food did not cater to his taste, he kept claiming that the meals were delicious in front of the host when he said he was eating and saying good-bye to him. American students think Chinese students have made false statements that make people sound hypocritical. He thought he would say something grateful if he encountered the same situation, but at the same time he would also be blunt to point out that the food failed to fit into his taste. In this regard, Chinese students explained that saying food is delicious is an expression of gratitude, not hypocritical compliment. In English culture, people are accustomed to showing admiration and gratitude for each other in different verbal acts. If they are to be praise others, they use commentary, limited and high-profile compliments; Chinese people's behavior under the same circumstance is totally different, when facing the same object, when it praised, the words of gratitude without evaluation, all-round affirmative and low-profile compliments given by them are often regarded as being overly modest by the westerners, which is a manifestation of hypocrites and flattery.

The difference between traditions and values are also reflected in the different notions of the same testimonies. A culture that is generally accepted or perceived to be of value is not recognized or discarded in another culture; a culture considered civilized and appropriate language is considered to be backward and rude in another culture. This is showing in the following specific perspectives:

This is a topic that appears frequently in both languages. In the past, "you are fatter than before" is a compliment when Chinese people met others, but now many people would like to be told that "you are thinner" as the improvement of people's living standards has brought about health and aesthetic needs. But it can not be denied that under the influence of traditional culture, to say some one is "fatter" still contains the meaning of complimenting his superiority in living conditions. Meanwhile, when you arguing one is "thin", it generally shows concerning about his physical condition. However, the corresponding meaning cannot be found in English culture, instead, people 
regard weight as a sign of health, so claiming one is fat will be understood as alluding to his physical decline, but "thinner" is without doubt a compliment.

For the Chinese, praising each other's economy is a form of compliment, in many cases complimenting reflect that people are envious of them; in English-speaking cultures, people value the wealth acquired by individual efforts.

People in both Chinese and English cultures value friendship. However, Chinese people's interpersonal relationships tend to be emotionally oriented. They think that friends, especially good friends, should help each other and make mutual righteousness, so we often hear compliment as "true brothers", which is not heard in English culture. In the context of English culture, the orientation of interpersonal relationships is centered on work and aspirations. The friendships still emphasize independence, autonomy and competition without mutual obligations and responsibilities. Therefore, it is understandable that a person have not helped a friend who is in difficulty.

Most Chinese women feel embarrassed and sometimes unjust when they receive praise of the opposite sex on their appearances in public. In English, people's praise of women's appearance and clothing is very common and natural, and the open degree is relatively free, basically not subject to age, occasion and level of familiarity.

Under the different backgrounds of Chinese culture and English culture, attitudes and reactions to compliments are also very different. In the English culture, we adopt more direct and readily accepted methods, rarely negate them, so as not to reveal inconsistencies with the people who make compliments and then make others embarrassed. The Chinese people's response to compliments is quite different. "Be humble to show respects to people" is a concrete embodiment of "courtesy" in the context of China under certain circumstances, which means elevating others and belittling themselves. Therefore, Chinese usually like to use negative or reserved reservations, thus forming some special nongovernmental statements in verbal communication, such as "I do not deserve such praise"'" and "You spoke too highly of me" and so on, which are more euphemistic and subtle.

The response to praise is generally divided into accepting and rejecting. Chinese and English have very different meanings in compliment responses because of different traditional values and ways of thinking. Let's look at the following examples.

Example 1: Student A: "Wow, today's speech is really wonderful! Our classmates all praise it!" Student B: "No, mine is not so good." In Example 1, Student B heard a classmate commend his speech, he said "no", with a rejected strategy to respond to the praise of a student. The strategy of using rejection as a response to compliment is frequently used in Chinese. This tactic met the humble norms of the politeness principle of minimizing compliments on itself and trying to exaggerate its own derogatory but contrary to agreeing with the guidelines that no positive evaluation of others was approved. This refusal to compliment a language is often considered impolite in English communication, whereas in Chinese language, people are more likely to consider compliance with modesty as a result of traditional culture. In the conversation to minimize or even deny their own praise, such a response strategy was considered polite.

Example 2: Mr. Wang: "Mr. Li's handwritings are powerful and magnificent, it is clear that you are a really master!" Mr. Li: "You spoke highly of me! Compared with yours, mine is not worthy mentioning!" In this example, facing Mr. Wang's praise of his own handwritings, he adopted self-deprecating way to respond. Such Chinese response strategies for complimenting words violate the criteria of approval in the politeness principle. Although they do not agree with the positive evaluation of others, such response strategies follow the principle of modesty, and the people who make compliments is going to try to exaggerate their derogatory to show your courtesy. This is mainly influenced by the idea of "degrading oneself and respect others" in Chinese traditional culture. Therefore, in response to the compliment, Chinese generally neglect to agree with the norms and choose modest guidelines that are more in line with their own cultural traditions as polite words. 


\section{Inspiration}

Through the above comparative analysis of the Chinese-English compliment response examples, we can see that Chinese and English have great differences in the compliment response strategies. In this paper, the compliment norms, humble norms and criteria of approval in Leech's politeness theory are combined with the examples of conversations in Chinese and western social interactions, and analyzed separately, revealing different manners of politeness under the influence of the two cultures. Chinese culture is based on collectivism, then personal values and functions are followed. It is generally accepted that the form of ceremony is to demean oneself, so people pay more attention to self-humility in social interaction and tend to refuse in response to compliments. The Western culture is based on the individualism, emphasizing personal values and roles, so people in social interaction more inclined to accept the praise. In communicating with people from different cultural countries, we should strengthen our awareness of cultural differences, cultivate pragmatic competence and promote the success of communication. Foreign language teaching workers should also consciously cultivate their awareness of cultural differences, and focus on pragmatic competence in the teaching process.

From the above analysis, we can conclude that we should cultivate students with cultural awareness in teaching Chinese as a foreign language, especially the cultivation of some appellations, taboos and compliments. Only in this way can their daily communication be smooth, and a lot of unnecessary troubles caused by communication obstacles can be reduced. Of course, it is quite difficult to establish a new cultural paradigm in the minds of students because students already have a stereotype of Chinese culture. As a teacher of Chinese as a foreign language, we should introduce Chinese culture as comprehensive as possible in teaching, overcome cultural stereotypes of students, abandon cultural discrimination and make students have an objective grasp of Chinese culture.

In short, in teaching Chinese as a foreign language, both teachers and students should pay attention to cultural differences as well as mutual respect, mutual understanding and mutual adaptation of cultural differences. Only in this way, people with different cultural backgrounds can avoid verbal misunderstanding and even conflict in intercultural communication, which is conducive to the smooth progress of communication.

\section{References}

[1] Zhong Weijie. Exploration of Innovative Development of English Majors [J]. Foreign Language Teaching and Research, 2014, (01): 127-133 + 160 .

[2] Wang Xiaoyin. Study on the Quality of Chinese as a Foreign Language Teacher [D]. Shaanxi Normal University, 2013.

[3] Wang Fang. A new exploration of the language characteristics of primary language teaching [J]. Zibo Teachers' College, 2011, (02): 11-14.

[4] Zhou Mingjuan. Comparison of English and Chinese Compliments in Cross-cultural Communication [J]. Journal of Liaocheng University (Social Sciences), 2005, (03): 157-158.

[5] Leech, G (1983) Principle of pragmatics London Longman.

[6] Levinson, S.C. (1987). Pragmatics, Cambridge Unversity Press.

[7] Wolfson, Nessa (1990). Rules of Speaking, Language and Communication. Longman Group limited

[8] Pengzeng an intercultural language communication - Second Language Acquisition and Teaching of Chinese [M]. Xue Lin Publishing House, 2007.

[9] Li Xiaoqi. Teaching Chinese as a foreign language teaching [M]. Commercial Press, 2006. 